\title{
When does the patient with a disc herniation undergo lumbosacral discectomy?
}

\author{
Patrick C A J Vroomen, Marc C T F M de Krom, J Andre Knottnerus
}

\begin{abstract}
Objectives-To design a model that could accurately predict eventual lumbar disc surgery in the patient initially presenting with clinical findings of nerve root compression.

Methods-Prospective study in 183 patients with nerve root compression sampled from a primary care population. All patients underwent a standardised history, physical examination, and MRI. Surgery carried out in the next 6 months was recorded. Models were constructed to predict whether patients eventually received surgery.

Results-Two models were constructed. Reduced model A was based on baseline findings, only, and contained six variables. Model B incorporated change over time as well and contained 10 variables. The area under the curve (in a receiver operating characteristic) for these models was $\mathbf{0 . 8 6}$ and 0.92 , respectively. It was shown that at a probability cut off of 0.60 , model $B$ predicted eventual surgery with a sensitivity of $57 \%$ and a specificity of $100 \%$.

Conclusions-Given the requirement of a high specificity, eventual operation could be adequately predicted in a sample of 183 patients with clinical nerve root compression. The application of the model in patients with nerve root compression might lead to earlier operation in a subset of patients resulting in a reduction of duration of illness and associated indirect costs. An important prerequisite for future application would be the validation of the prediction rule in another population. (F Neurol Neurosurg Psychiatry 2000;68:75-79)
\end{abstract}

Neurology, Maastricht

University Hospital,

Maastricht, The

Netherlands

P C A J Vroomen

M C T F M de Krom

Department of General Practice, Maastricht University, Maastricht, The

Netherlands

J A Knottnerus

Correspondence to: Dr Patrick C A J Vroomen, Maastricht University Hospital, P Debyelaan 25, PO Box 5800, 6202 AZ

Maastricht, The Netherlands

Received 8 September 1998 and in final form

18 June 1999

Accepted 28 June 1999 surgical therapy; discectomy; prediction

Several papers support the effectiveness of lumbosacral discectomy in patients with clinical findings of nerve root compression. ${ }^{1-4}$ Those clinical findings as highlighted in various papers ${ }^{5-8}$ should then be supported by radiological images of nerve root compression. ${ }^{9-15}$ The issue raised by these papers is how high the likelihood of clinical and radiological nerve root compression should be to warrant operation. ${ }^{16}$ The optimal likelihood depends on the situation and the patients' and doctors' preferences. Even patients with near certain nerve root compression are not automatically operated on, however. The nerve root compression should be sufficiently bothersome for surgery to be considered by both patient and treating physician. Finally, the complaints of nerve root compression should have existed for a sufficient time period before surgery is considered. What is a sufficient time? In view of the favourable natural course of clinical nerve root compression, ${ }^{17-20}$ and the possible complications of surgery, most physicians will probably prefer to continue conservative treatment for at least 6 weeks. If there were a way of predicting an eventual poor outcome of conservative therapy with the subsequent need for surgery at the time that the patient initially presents, time intervals until surgery might be shortened in a subset of patients.

In a prospective study, patients with clinical findings indicating nerve root compression were investigated with regard to findings that might predict the future need for operation. This prediction was evaluated by logistic regression at two stages: (1) how could future surgery be predicted at the first consultation (model A), and (2) how could it be predicted at a second consultation after 2 weeks taking into account the disease course over 2 weeks (model B). As the benefits of these predictions might expediate MRI studies and eventual surgery, we assumed that the model used to expediate MRI studies should have a specificity exceeding $95 \%$ (limiting the rate of MRI studies done in patients that would eventually not be operated to $5 \%$ ) and the model used to expediate surgery should have a specificity of nearly $100 \%$ (so that no patients would be operated on as a result of the model's predicition that would otherwise not be operated on). The value of the predictive models was estimated to indicate whether future validation of the models in additional research would be useful.

Keywords: nerve root compression; disc displacement;

\section{Patients and methods}

STUDY POPULATION

Between February 1995 and December 1996, 50 general practitioners (GPs) in Maastricht and surrounding villages asked patients to participate in a study on sciatica. Patients were referred to the neurology department of the Maastricht University Hospital if they presented for the first time with the current episode of pain radiating into the leg below the gluteal fold of sufficient intensity. They were excluded for previous spinal surgery, pregnancy, confinement in prison, unavailability for follow up visits (moving plans, severe disease), and severe comorbidity. The researchers reviewed the selection criteria and applied two further criteria: patients were to have symptoms of and signs of lumbar nerve root involvement (at least two of the following signs and 
symptoms: typically radicular pain distribution, pain in the leg increasing with coughing, sneezing, or straining, decreased muscle strength, sensory loss, reflex loss, positive nerve tension test). They were excluded if there was an indication for direct surgical intervention (either morphine dependent, intractable pain, progressive, severe decreased paresis of limited duration, or cauda equina syndrome).

BASELINE EXAMINATIONS

All patients selected were examined within 2 days of referral by the GPs and again 2 weeks later. At stage 1, two classes of independent variables were investigated for their predictive value:

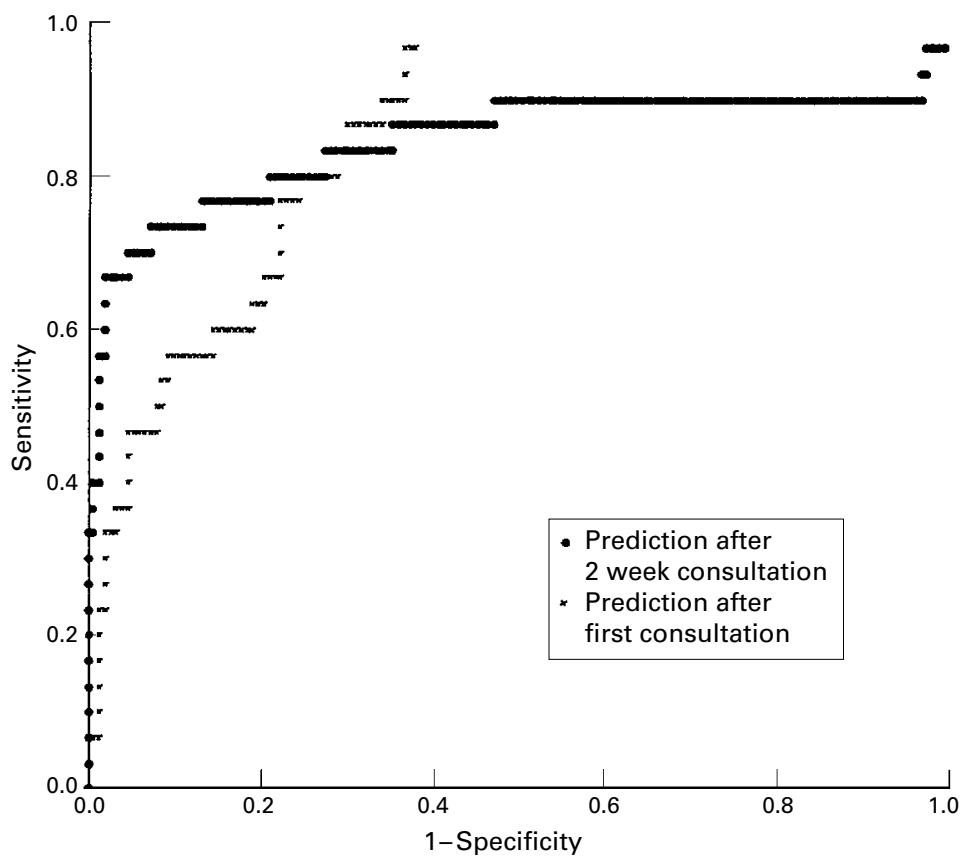

Figure 1 ROC Curves for the prediction of eventual surgery by model $A$ and $B$. $R O C=$ receiver operating characteristic.

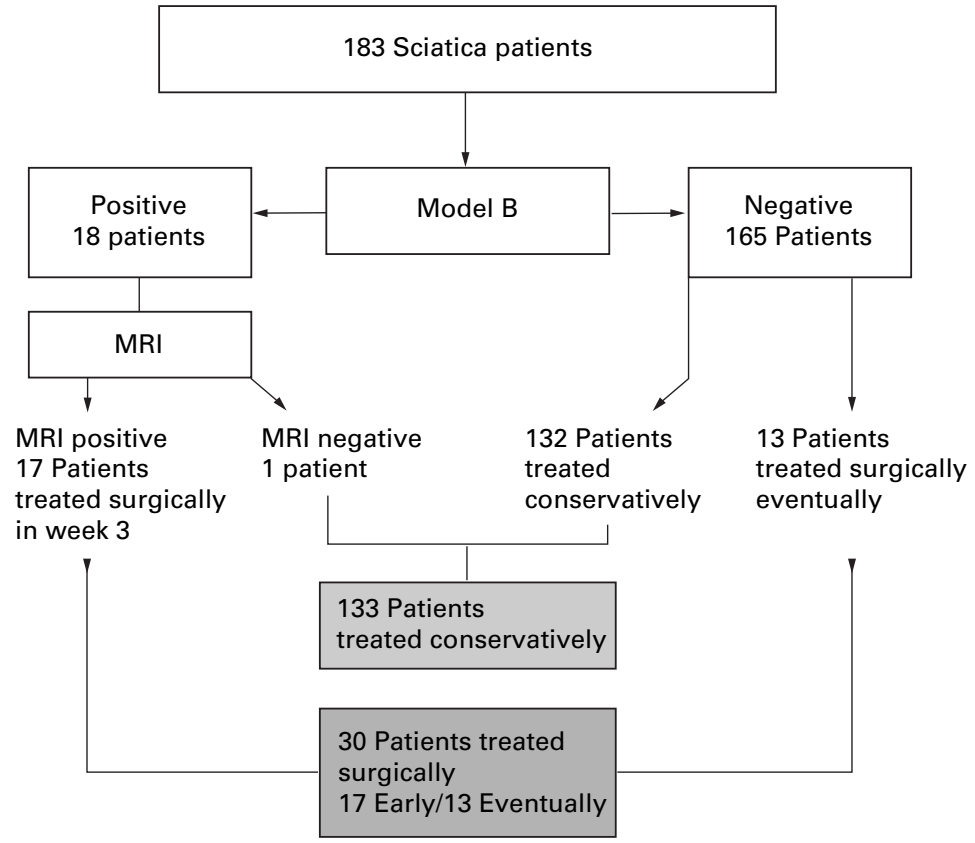

Figure 2 An example of model B application.
STAGE 1: HISTORY/QUESTIONNAIRE ITEMS

These were age, sex, high education level, living alone, mentally demanding job type, previous episodes of pain in the leg, previous episodes of low back pain, family history, comorbidity, smoking, sports activities, exercised back or abdominal muscles, more pain in leg than back, sudden onset of pain, cause of pain known, pain worse in the evening or night, paroxysmal pain, pain already improving, typically dermatomal pain distribution, more pain on coughing, sneezing, or straining, more pain on sitting, numbness in the leg, paraesthesias in the leg, cold feeling in the leg, worrying about health, intensity of pain in the leg scored by the patient on a visual analogue scale (VAS), complaints considered severe by the physician, pain rating index of McGill pain questionnaire ${ }^{21}$ for sensory and affective dimensions (PRI-S and PRI-A), questionnaire items difficulty putting on socks/stockings, and pain while dressing.

STAGE 2: PHYSICAL EXAMINATION ITEMS

These were finger-floor distance, paresis, hypaesthesia, hypalgesia, ankle tendon reflex difference, knee tendon reflex difference, straight leg raising (SLR; the test was positive if there was typically dermatomal pain on straight leg raising at an angle less than $45^{\circ}$ ), reversed SLR, crossed straight leg raising, Kemp sign, Naffziger sign.

Additionally, it was investigated how much predictive value would be gained by reevaluating the patient after 2 weeks, thereby taking the time course into account. The second stage analysis incorporated results of the 2 week follow up visit (instead of baseline values) for typically dermatomal pain distribution, pain worse on sitting, SLR, and crossed SLR. Also, for pain intensity in the leg the change of VAS over 2 weeks was assessed instead of the VAS at baseline. The PRI-A of the McGill pain questionnaire after 2 weeks was investigated instead of the PRI-A at baseline.

\section{STATISTICAL ANALYSIS}

Backward stepwise logistic regression analysis ${ }^{22}$ with the likelihood ratio test on SPSS software was used to predict surgical intervention in the next 6 months. At the first stage, set I was modelled. Then, set II was modelled also incorporating the predictive variables from the model of set I. The resulting reduced models were based on data collected at first consultation and predicted the likelihood of surgery in the next 6 months. The probability of surgery for each patient can be estimated using the formula below table 2 . At any given probability cut off, some patients will be below the cut off and some above. These numbers can be compared with the numbers actually operated in a $2 \times 2$ table. In this way, sensitivity and specificity values can be calculated for any probability cut off value. The (1-specificity) versus sensitivity values for the various probability cut offs of both models are depicted in the receiver operating characteristic ${ }^{2324}$ in figure 1 . The area under the curve was 
Table 1 Baseline patient characteristics $(n=183)$

\begin{tabular}{|c|c|c|}
\hline Patient characteristics & $\begin{array}{l}\text { Mean/ } \\
\text { distribution } \\
\%\end{array}$ & $(S D)$ \\
\hline Age & 46 & $(12)$ \\
\hline Male sex & 56 & \\
\hline Duration of pain (median in days) & 16 & \\
\hline 14 days or less & 48 & \\
\hline $15-30$ days & 26 & \\
\hline More than 30 days & 26 & \\
\hline Any previous episode of pain in the leg & 37 & \\
\hline Any previous episode of low back pain & 73 & \\
\hline \multicolumn{3}{|l|}{ Visual analogue scale $(\mathrm{mm})$} \\
\hline Major complaint & 85 & (17) \\
\hline Pain in the leg & 65 & (21) \\
\hline Low back pain & 47 & (32) \\
\hline \multicolumn{3}{|l|}{ McGill pain questionnaire: } \\
\hline PRI-A & 3.7 & (3.1) \\
\hline PRI-S & 10.0 & $(5.8)$ \\
\hline Paresis & 18 & \\
\hline Sensory loss & 42 & \\
\hline \multicolumn{3}{|l|}{ Reflex differences } \\
\hline Ankle tendon & 20 & \\
\hline Knee tendon & 7 & \\
\hline Nerve root compression on MRI & 59 & \\
\hline Comorbidity & 34 & \\
\hline \multicolumn{3}{|l|}{ Sports: } \\
\hline No & 56 & \\
\hline 1-2 hours/week & 24 & \\
\hline 3 or more hours/week & 20 & \\
\hline Employed & 61 & \\
\hline Receiving worker's compensation & 8 & \\
\hline Requiring surgery in next 6 months $(n=30)$ & 16 & \\
\hline
\end{tabular}

Table 2 Reduced model A: the variables at first consultation predicting surgery (multiple logistic regression analysis with eventual surgery as dependent variable)

\begin{tabular}{lllll}
\hline Baseline predictors of surgery & $\begin{array}{l}\text { Crude } \\
\text { odds ratio }\end{array}$ & $95 \%$ CI & $\begin{array}{l}\text { Adjusted } \\
\text { odds ratio }\end{array}$ & $95 \%$ CI \\
\hline $\begin{array}{l}\text { History/questionnaire: } \\
\text { Mentally demanding job }\end{array}$ & 3.8 & $1.7-8.6$ & 4.0 & $1.5-10.3$ \\
$\begin{array}{l}\text { Sudden onset } \\
\text { More pain on coughing/sneezing/straining }\end{array}$ & 0.28 & $0.1-0.7$ & 0.22 & $0.07-0.68$ \\
$\begin{array}{l}\text { Difficulty putting on socks/stockings } \\
\text { VAS of pain intensity in the leg }\end{array}$ & 1.6 & $2.0-13.6$ & 4.3 & $1.5-12.4$ \\
$\begin{array}{l}\text { Physical examination: } \\
\text { Reversed straight leg raising }\end{array}$ & 1.03 & $1.0-1.05$ & 1.033 & $1.004-1.062$ \\
Exponential value of the intercept & 2.5 & $1.1-5.8$ & 3.2 & $1.2-8.9$ \\
& $3.6^{\star} 10^{-3}$ & $2.9^{\star} 10^{-4}-4.4^{\star} 10^{-2}$ & \\
\hline
\end{tabular}

$\overline{\text { VAS = visual analogue scale; crude odds ratio=the association between two variables calculated as }}$ the odds of a finding being present in the case of eventual surgery divided by the odds of a finding being absent in the absence of eventual surgery (with odds being defined as the probability that the event will occur divided by the probability that the event will not occur). In diagnostic research this odds ratio is often referred to as the likelihood ratio. Logistic regression analysis is an alternative method of calculating odds ratios; adjusted odds ratio=the association between two findings adjusted for the confounding effect of other findings. Logistic regression has the additional benefit that in a multivariate analysis the presence or absence of a finding can be related to more than one factor. The following paradigma holds for the calculation of the probability of surgery in the next 6 months:

Probability $(\mathrm{X})=1 /\left(1+\mathrm{e}^{-\mathrm{Y}}\right)$

$\mathrm{Y}=\alpha+\ln (4)^{\star} \mathrm{X} 1+\ln (0.22)^{\star} \mathrm{X} 2+\ln (4.3)^{\star} \mathrm{X} 3+\ln (2.3)^{\star} \mathrm{X} 4+\ln (1.033)^{\star} \mathrm{X} 5+\ln (3.2)^{\star} \mathrm{X} 6$

$\alpha=$ intercept and $\mathrm{X} 1$ through $\mathrm{X} 6$ are the six variables in the order of the table.

Table 3 Reduced model B: the variables at second consultation predicting surgery (multiple logistic regression analysis with eventual surgery as dependent variable)

\begin{tabular}{|c|c|c|c|c|}
\hline Baseline predictors of surgery & $\begin{array}{l}\text { Crude } \\
\text { odds ratio }\end{array}$ & $95 \% C I$ & $\begin{array}{l}\text { Adjusted } \\
\text { odds ratio }\end{array}$ & $95 \% C I$ \\
\hline \multicolumn{5}{|l|}{ History/questionnaire: } \\
\hline \multicolumn{5}{|l|}{ Duration of disease at presentation: } \\
\hline $15-30$ days & 3.4 & $1.3-8.7$ & 5.8 & $2.7-12.5$ \\
\hline More than 30 days & 1.8 & $0.7-5.1$ & 1.2 & $0.6-2.7$ \\
\hline Previous episodes of pain in the leg & 1.0 & $0.4-2.3$ & 0.17 & $0.08-0.3$ \\
\hline Previous episodes of low back pain & 2.8 & $0.9-2.1$ & 7.3 & $2.8-19.2$ \\
\hline \multicolumn{5}{|l|}{ Positive family history for: } \\
\hline Pain in the back & 3.3 & $0.9-12.4$ & 10.1 & $3.2-31.2$ \\
\hline Pain in the leg & 1.0 & $0.4-0.9$ & 4.1 & $1.9-8.7$ \\
\hline Mentally demanding job & 3.8 & $1.7-8.6$ & 4.4 & $2.3-8.2$ \\
\hline Paraesthesias & 0.5 & $0.2-1.2$ & 0.2 & $0.08-0.36$ \\
\hline Pain worsening on sitting after 2 weeks & 4.4 & $0.6-2.3$ & 24.3 & $9.6-62$ \\
\hline Change over 2 weeks in VAS of leg pain & 1.05 & $1.02-1.07$ & 1.058 & $1.040-1.076$ \\
\hline PRI-A of McGill pain questionnaire & 1.3 & $1.1-1.4$ & 1.35 & $1.22-1.49$ \\
\hline \multicolumn{5}{|l|}{ Physical examination: } \\
\hline Crossed straight leg raising & 2.1 & \multirow{2}{*}{\multicolumn{2}{|c|}{$\left(5.3^{\star} 10^{-4}-1.1^{\star} 10^{-2}\right)$}} & $1.8-10.2$ \\
\hline Exponential of the intercept & $2.3^{\star} 10^{-3}$ & & & \\
\hline
\end{tabular}

Footnotes as for table 2. estimated non-parametrically. This area reflects the overall predictive properties of each model. At the second stage, variables investigated at the 2 week consultation were also taken into account. The predictive properties of this model were also investigated using an ROC curve (figure 1). The probabilities at which the specificity would be $95 \%$ and $100 \%$ were determined. To illustrate the possible consequences of applying the models using these probabilities, an example was worked out in which patients would indeed receive the predicted surgery at an early stage (figure 2 ).

\section{Results}

Twenty nine of 212 eligible patients declined participation. They had slightly less severe disease (as scored on the VAS by the observer) and a somewhat lower score on the affective dimension of the McGill pain questionnaire. ${ }^{21}$ one hundred and eighty three patients were eventually included. Two patients did not return after 2 weeks; both reported improvement. After 3 months a total of 14 patients were lost to follow up, yet data on whether operation occurred was gathered for all 14 patients. Their baseline characteristics and success rate after 2 weeks were similar to the 169 remaining patients. The characteristics of the 183 patients selected are shown in table 1 . Thirty patients eventually had surgery.

Overall, the eventual need for surgical intervention could be accurately predicted. Table 2 shows 6 baseline variables that independently predicted eventual surgery: a mentally demanding job, sudden onset of pain, more pain on coughing, sneezing, or straining, difficulty putting on socks or stockings, VAS of pain intensity in the leg, and the reversed straight leg raising test. Together with the intercept they formed the reduced logistic model A. Table 3 shows model B based on both baseline data and the data after 2 weeks as well as the change over time. The predictors were: duration of disease, previous episodes of low back pain or pain in the leg, a positive family history for low back pain or pain in the leg, a mentally demanding job, paraesthesias, a pain worsening on sitting after 2 weeks, the pain intensity in the leg on a VAS, PRI-A of the McGill pain questionnaire, and the crossed SLR. The predictive properties are further summarszed by the receiver operating characteristic (ROC) curves in figure 1 . Overall, model B provided a better prediction of surgery than model $\mathrm{A}$. The area under the curve was 0.86 for model $\mathrm{A}$ and 0.93 for B. Figure 1 also shows that model A may be preferred, when a very sensitive (few false negatives, upper right corner of ROC) prediction is called for, and model $\mathrm{B}$ may be preferred, when a high specificity (few false positives, lower left corner) is the purpose.

\section{Discussion}

Our study shows that it is possible to predict eventual surgery in patients with sciatica. Already at first consultation, several characteristics of patients with sciatica predict the eventual need for surgery. A mentally demanding job (as opposed to a mentally non-demanding 
job or no job), a gradual onset of pain, an increase of pain on coughing, sneezing, or straining and difficulty putting on socks or stockings are the four history items predicting surgery. Of the physical examination findings, solely a reversed straight leg raising test (SLR) predicts surgery. Of these findings, only an increase of pain on pressure and the reversed SLR are generally considered to be findings of nerve root compression.

The model based on first and second consultation allowed an even better prediction of surgery; the area under the curve was 0.93 for model $\mathrm{B}$ versus 0.86 for model $\mathrm{A}$. Strikingly, only three of the predictors in the model generally regarded as indicators of nerve root compression predicted surgery: paraesthesias, pain increasing on sitting and a crossed SLR. Another remarkable finding is that model $B$ contains other baseline variables than in model A. Some variables in model A may predict eventual surgery partly because they predict poor outcome after 2 weeks. In a model with outcome measures after 2 weeks, such variables will lose part of their predictive value. On the other hand, the duration of disease contributes to the model only if the outcome after 2 weeks is accounted for. Meanwhile, it reflects that for most patients about 4-6 weeks of complaints will have passed by before surgery is considered. Interestingly, patients with previous episodes of back pain are more likely to undergo surgery, whereas patients with previous episodes of leg pain are less likely. The latter group's experience with previous sciatica episodes that have resolved without surgery may decrease their inclination towards surgery. On the contrary, patients that have had low back pain before, may be more disconcerted by the new experience of radiating pain into the leg. Patients in mentally demanding professions may be more likely to undergo surgery because of a more assertive attitude towards surgeons, or because surgeons may be more willing to operate on working patients that are not in physically demanding jobs. In this respect, it is also striking that patients with a higher score on the affective dimension of the McGill pain questionaire are more likely to undergo surgery. Finally, the change over time of pain intensity in the leg is a strong predictor. It seems logical that pain levels after 2 weeks in comparison to the baseline levels are related to the likelihood of surgery.

After having stated that surgery can be predicted, an important question is how good the predictive properties of the models are. According to the ROC curves and their corresponding areas under the curve, the overall predictive value is high. The following paragraph will illustrate the potential clinical relevance of the model.

Probability cut off values can be chosen to suit the particular demand. If patients are very likely to eventually undergo operation, it might be desirable not to wait until this indeed happens, but to operate at an earlier time. If the latter decision were based on the model, the probability cut off would have to have a very high specificity. Every false positive prediction would imply a patient operated on who would otherwise not have been operated on. A specificity of $100 \%$ was possible for model A, but with a sensitivity of only $7 \%$. Hypothetically, model A might then reliably expediate surgery, but only in $7 \%$ of the patients that eventually received surgery. For model $\mathrm{B}$, the probability cut off with a $100 \%$ specificity was 0.60 . The sensitivity of this probability value was $57 \%$. This means that surgery might be expediated in 17 of 30 patients eventually operated on. This seems a relevant gain.

If this positive prediction had resulted in operation in week 3 instead of further awaiting the natural course, the total waiting time for these 17 would have been 17 instead of 117 weeks. Thus, for 30 patients operated on, 100 weeks of waiting time could be gained if the models were applied. With an employment rate of $60 \%$, estimated indirect costs of 500 dollars/ week related to waiting, and an annual operation rate of 20000 in the United States, a gain of 3.3 weeks per patient would amount to saving 20 million dollars of indirect costs per year in the United States alone.

There are several reasons why the models cannot be directly applied, however. Firstly, determining the diagnostic properties of a prediction rule in the population from which it was derived will likely overestimate the predictive value. Such a prediction rule should first be validated in another study population. Secondly, the prediction rule was formulated for a population directly derived from primary care. It remains to be shown whether the characteristics of the prediction rule can be extrapolated to more selected secondary care populations. ${ }^{25}$ Finally, the prediction rule is dependent on the indications for surgery currently applied in our hospital. If other indications for surgery are used, the predictive rule may no longer hold. The models only show that given a set of indications (namely, those in our hospital) eventual surgery in sciatica can be predicted. Importantly, most of the predictors do not seem to be obvious indications for surgery. The nature of the predictors in the model and particularly the striking lack of classic indicators of nerve root compression suggest that many non-medical factors influence the decision to operate. It is not unlikely that this is a universal situation.

1 Atlas SJ, Deyo RA, Keller RB, et al. The Maine lumbar spine study, part II: 1 year outcomes of surgical and nonsurgical management of sciatica. Spine 1996;21:1777-86.

2 Hoffman RM, Wheeler KJ, Deyo RA. Surgery for herniated discs: a literature synthesis. F Gen Intern Med 1993;8:48796.

3 Weber H. Lumbar disc herniation; a controlled, prospective study with 10 years of observation. Spine 1983;8:131-40.

4 Mixter WJ, Barr JS. Rupture of the intervertebral disc with involvement of the spinal canal. N Engl F Med 1934;211: 210-5.

5 Deyo RA, Rainville J, Kent DL. What can the history and physical examination tell us about low back pain? $f A M A$ 1992;268:760-5.

6 Andersson GBJ, Deyo RA. History and physical examination in patients with herniated lumbar discs. Spine 1996;21(24S): 10S-18.

7 Hoogen HJMM, Koes BW, Eijck JTMv, et al. On the accuracy of history, physical examination, and erythrocyte sedimentation rate in diagnosing low back pain in general practice. Spine 1995;20:318-27.

8 Vroomen PCAJ, de Krom MCTFM, Knottnerus JA. Diagnostic value of history and physical examination in patients nostic value of history and physical examination in patients Neurology 1999 (in press). 
9 Herzog RJ. The radiologic assessment for a lumbar disc herniation. Spine 1996;21(24S):19S-38

$10 \mathrm{Kim}$ KY, Kim YT, Lee CS, et al. MRI classification of lumbar herniated intervertebral disc. Orthopedics 1992;15:493-7.

11 Jackson RP, Cain J Jr, Jacobs RR, et al. The neuroradiographic diagnosis of lumbar herniated nucleus pulposus: II A comparison of computed tomography (CT), myelography, CT-myelography, and magnetic resonance imaging. Spine 1989;14:1362-7.

12 Albeck MJ, Hilden J, Kjaer L, et al. A controlled comparison of myelography, computed tomography, and magnetic resonance imaging in clinically suspected lumbar disc herniation. Spine 1995;20:443-8.

13 Ellenberger C. MR imaging of the low back syndrome. Neurology 1994;44:594-600

14 Jensen MC, Brant-Zawadzki $\mathrm{MN}$, Obuchowski $\mathrm{N}$, et al. Magnetic resonance imaging of the lumbar spine in people without back pain. N Engl F Med 1994;331:69-73.

15 Jönsson B, Strömqvist B. Symptoms and signs in degeneration of the lumbar spine. A prospective, consecutive study of
300 operated patients. F Bone foint Surg Br 1993;75:381-5.

16 Larequi-Lauber T, Vader J-P, Burnand B, et al. Appropriateness of indications for surgery of lumbar disc hernia and spinal stenosis. Spine 1996;22:203-9.
17 Weber H, Holme I, Amlie E. The natural course of acute sciatica with nerve root symptoms in a double-blind
placebo-controlled trial evaluating the effect of piroxicam. Spine 1993;18:1433-8.

18 Vroomen PCAJ, Krom MCTFMd, Wilmink JT, et al. Lack of effectiveness of bed rest for sciatica. N Engl fै Med 1999; 340:318-23.

19 Saal JA, Saal JS, Herzog RJ. The natural history of lumbar intervertebral disc extrusions treated non-operatively. Spine 1990;15:683-6.

20 Komori H, Shinomiya K, Nakai D, et al. The natural history of herniated nucleus pulposus with radiculopathy. Spine 1996;21:225-9.

21 Melzack R, Katz J. The McGill pain questionnaire: appraisal and current status. In: Turk DC, Melzack R, eds. Handbook of Pain Assessment. New York: Guildford Press, 1992:15268 .

22 Kleinbaum DG. Logisitic regression: a self-learning text. 1st ed. New York: Springer, 1994

23 Metz CE. Basic principles of ROC analysis. Semin Nucl Med 1978;8:283-98

24 Hanley JA. Receiver operating characteristic (ROC) methodology. Crit Rev Diagn Imaging 1989;29:307-35.

25 Knottnerus JA. Medical decision making by general practitioners and specialists. Fam Pract 1991;8:305-7. 